University of Nebraska - Lincoln DigitalCommons@University of Nebraska - Lincoln

2015

\title{
Compiled furnace cyclic lives of EB-PVD thermal barrier coatings
}

James L. Smialek

NASA Glenn Research Center, james.l.smialek@nasa.gov

Follow this and additional works at: http://digitalcommons.unl.edu/nasapub

Smialek, James L., "Compiled furnace cyclic lives of EB-PVD thermal barrier coatings" (2015). NASA Publications. 221.

http://digitalcommons.unl.edu/nasapub/221

This Article is brought to you for free and open access by the National Aeronautics and Space Administration at DigitalCommons@University of Nebraska - Lincoln. It has been accepted for inclusion in NASA Publications by an authorized administrator of DigitalCommons@University of Nebraska - Lincoln. 


\title{
Compiled furnace cyclic lives of EB-PVD thermal barrier coatings
}

\author{
James L. Smialek* \\ NASA Glenn Research Center, 21000 Brookpark Rd., Cleveland, OH 44135, United States
}

\section{A R T I C L E I N F O}

\section{Article history:}

Received 25 March 2015

Revised 13 May 2015

Accepted in revised form 11 June 2015

Available online 17 June 2015

\section{Keywords:}

Thermal barrier coatings

Cyclic oxidation

Superalloys

Spallation

Aluminides

\begin{abstract}
A B S T R A C T
Furnace cycling has been widely used to study the failure of EB-PVD thermal barrier coatings. This contribution compiles TBC furnace cyclic lives over a broad literature base to highlight optimum systems and generalized trends not always apparent in one study. Systems included typical bond coats (Pt-modified aluminides, diffused Pt-only $\gamma / \gamma^{\prime}$, and NiCoCrAlY ( \pm Pt, Hf) overlays) and superalloy substrates (1st, 2nd, 3rd generation single crystals, directionally solidified, or conventionally cast). Pretreatments included controlled low $\mathrm{p}\left(\mathrm{O}_{2}\right)$ bond coat pre-oxidation and grit blasting (or none). The aggregate lives $(\sim 70)$ suggest a general trend with temperature, $\sim 10$-fold decrease for every $100{ }^{\circ} \mathrm{C}$ increase. Measured alumina scale thicknesses ( 30) were, on average, $\sim 6.1 \pm 1.8 \mu \mathrm{m}$ at failure and independent of temperature for conventional systems. Most failures thus occurred in less time than that predicted to grow $7 \mu \mathrm{m}$ of alumina scale (as estimated from separate TGA studies of a Ptmodified aluminide coated 2nd generation single crystal superalloy). A tentative activation energy indicated from the broad distribution of failure times was $\sim 280 \mathrm{~kJ} / \mathrm{mol}$, while that from homogeneous TGA testing was $\sim 380 \mathrm{~kJ} / \mathrm{mol}$, with regression coefficients of $\mathrm{r}^{2}=0.57$ and 0.98 , respectively.
\end{abstract}

Published by Elsevier B.V.

\section{Introduction}

Thermal barrier coatings (TBCs) are widely used in the turbine industry to protect air cooled superalloy airfoils from direct exposure to the full gas temperature of the combustion gas. Yttria stabilized zirconia (YSZ) is commonly deposited by air plasma spray (APS) and electron beam physical vapor deposition (EB-PVD). Aircraft turbines typically employ the latter. Plasma sprayed NiCoCrAlY bond coats are generally necessary for APS TBCs, due to the surface roughness required for mechanical bonding of the top coat. EB-PVD, VPS, detonation gun NiCoCrAlY, and aluminide diffusion bond coats are more typically used for EB-PVD top coats, provided the surface finish of the bond coats is acceptably smooth. More specifically, Pt-modified, $\beta$-phase aluminide bond coats are widely reported to provide exceptional oxidation resistance and TBC durability. Pt is known to improve alumina scale adhesion to $\beta-\mathrm{NiAl}$, as well as to extend the oxidative durability of aluminide coatings. The latter effect stems from higher diffusional stability and ability to form alumina scales, even without aluminizing, as evidenced by the success of commercial low cost and $\gamma / \gamma^{\prime}$ Pt-only bond coatings [1,2] (Rickerby, Gleeson, and coworkers).

Given the notable engineering success, these systems have become the focus of intense research and sophisticated analyses. This has led to a deeper understanding of failure mechanisms and numerous new approaches to improve durability, as can be surmised from a number of valuable reviews [3-9], as well as the large body of exceptional studies from UCSB [27] (Tolpygo and Clarke), ORNL (Pint, Zhang,

\footnotetext{
* Corresponding author.

E-mail address: James.L.Smialek@nasa.gov.
}

Haynes et al.), and others cited below regarding alumina scale growth, Pt-modified aluminizing, bond coat oxidation and TBC failure mechanisms. TBC durability is often evaluated by a furnace cyclic test (FCT), having a strong oxidative component to failure. While self-consistent TBC failure data can be assumed for a given batch of coatings produced by the same process and tested at the same laboratory (albeit with some inherent variability according to a Weibull distribution, as proposed by Strangman) [10], there may be disjunctions arising from different coating or testing facilities. This leads to a degree of uncertainty in evaluating life data obtained for a specific system at a single temperature. In order to assess the performance of coating types as a whole, the failure lives from 30 + published investigations were compiled and categorized by test temperature. It is intended to provide a broader perspective of typical failure times for standard coatings and to highlight any sensitivity to various system or process modifications. Some of these modifications include vacuum or low $\mathrm{p}\left(\mathrm{O}_{2}\right)$ oxidizing pre-treatments, polished bond coats, or eliminating standard grit blasting or aluminizing. In a secondary emphasis, EB-PVD and VPS NiCoCrAlY bond coat data is included for comparison, often with a variety of process treatments including Hf-doping and Pt plating effects.

This compilation is also intended to contrast superalloy coating behavior with YSZ-coated oxidation resistant bulk substrates, such as doped $\mathrm{NiAl}(\mathrm{Zr}, \mathrm{Hf})$. Here the effects of interdiffusion and other thermomechanical instabilities between bond coats and substrates are precluded, while scale growth and thermal expansion issues between metals and oxides remain. In that regard, failure lives are compared to oxidative times predicted to obtain scales of a specified 'critical thickness,' typically around 5-10 $\mu \mathrm{m}$ [11-13], although other contributing factors must still be present. The original motivation of this compilation 
Table 1

Compiled furnace cycle life of EB-PVD YSZ thermal barrier coatings.

$\mathrm{T}=$ test temperature; $\mathrm{t}=$ failure time; $\mathrm{x}_{\mathrm{c}}=$ estimated/measured scale thickness at failure.

\begin{tabular}{|c|c|c|c|c|c|c|c|}
\hline Bond coat & Substrate & $\mathrm{T},{ }^{\circ} \mathrm{C}$ & $\mathrm{t}, \mathrm{h}$ & $\mathrm{x}_{\mathrm{c}}, \mu \mathrm{m}$ & Hot time/cycle & Study & \\
\hline \multicolumn{8}{|c|}{ a) No bond coat and Pt-Al bond coats } \\
\hline None & $\operatorname{NiAl}(\mathrm{Zr})$ & 1150 & 3800 & 14.6 & $1-\mathrm{h}$ & Pint & 2000 \\
\hline None & $\mathrm{NiAl}(\mathrm{Zr})$ & 1200 & $1700^{\mathrm{a}}$ & 11.0 & $2-\mathrm{h}$ & Pint & 2000 \\
\hline None & $\mathrm{NiAl}(\mathrm{Hf}, \mathrm{GaTi})$ & 1175 & $>1770$ & & $45 \mathrm{~min}$ & Rigney & 2000 \\
\hline None & Rene'N5 & 1100 & 2096 & & $45 \min$ & Yanar & 2011 \\
\hline $\mathrm{NiAl}(5 \mathrm{Cr}-0.5 \mathrm{Hf})$ & Rene'N5 & 1163 & 600 & & $45 \mathrm{~min}$ & Hazel & 2008 \\
\hline Pt-Al opt. & Rene'N5 & 1100 & 1530 & & $45 \mathrm{~min}$ & Yanar & 2011 \\
\hline Pt-Al SOA & Rene'N5 & 1100 & 839 & & $45 \mathrm{~min}$ & Yanar & 2011 \\
\hline Pt-Al SOA & Rene'N5 & 1200 & 96 & & $45 \mathrm{~min}$ & Yanar & 2011 \\
\hline Pt-Al & Rene'N5 & 1150 & 650 & 4.5 & $1-\mathrm{h}$ & Pint & 1998 \\
\hline Pt-Al & Rene'N5 & 1200 & 212 & 5.6 & $2-h$ & Pint & 1998 \\
\hline Pt-Al & Rene'N5 & 1150 & 907 & 7.6 & $1-\mathrm{h}$ & Pint & 2015 \\
\hline Pt-Al & Rene'N5 & 1163 & 173 & & $45 \mathrm{~min}$ & Hazel & 2008 \\
\hline Pt-Al & Rene'N5 & 1150 & 260 & 2.6 & 1-h & Smialek & 2008 \\
\hline $\mathrm{Pt}-\mathrm{Al}$ & Rene'N5 & 1100 & 974 & & $1-\mathrm{h}$ & Kim & 2002 \\
\hline Pt-Al & Rene'N5 & 1200 & 107 & & $1-h$ & Kim & 2002 \\
\hline Pt-Al & Rene'N5 & 1163 & 234 & & $45 \mathrm{~min}$ & Jackson & 2014 \\
\hline Pt-Al & Rene'N5 & 1163 & 271 & & $1-\mathrm{h}$ & Zhu & 2012 \\
\hline Pt-Al & Rene'N5 & 1163 & 225 & & $45 \mathrm{~min}$ & Zhu & 2004 \\
\hline Pt-Al & Rene $^{\prime} \mathrm{N} 5^{\mathrm{b}}$ & 1163 & 280 & & $45 \mathrm{~min}$ & Zhu & 2004 \\
\hline Pt-Al & Rene $^{\prime} \mathrm{N} 5^{\mathrm{b}}$ & 1163 & 333 & & $1-\mathrm{h}$ & Zhu & 2012 \\
\hline Pt-Al & Rene $^{\prime} \mathrm{N} 5^{\mathrm{b}}$ & 1150 & 300 & 2.9 & $1-h$ & Smialek & 2008 \\
\hline Pt-Al & CMSX-4 & 1100 & 1046 & 8.6 & $45 \mathrm{~min}$ & Sridharan & 2005 \\
\hline Pt-Al & CMSX-4 & 1121 & 514 & 6.9 & $45 \mathrm{~min}$ & Sridharan & 2005 \\
\hline Pt-Al & CMSX-4 & 1121 & 514 & 9.8 & $24 \mathrm{~h}$ & Sridharan & 2005 \\
\hline $\mathrm{Pt}-\mathrm{Al}$ & CMSX-4 & 1150 & 280 & 8.1 & $45 \mathrm{~min}$ & Sridharan & 2005 \\
\hline $\mathrm{Pt}-\mathrm{Al}$ & CMSX-4 & 1100 & 622 & 4.6 & $40 \mathrm{~min}$ & Wen & 2006 \\
\hline Pt-Al & CMSX-4 & 1121 & 307 & 5.3 & $40 \mathrm{~min}$ & Wen & 2006 \\
\hline Pt-Al & CMSX-4 & 1151 & 118 & 4.9 & $40 \mathrm{~min}$ & Wen & 2006 \\
\hline $\mathrm{Pt}-\mathrm{Al}$ & CMSX-4 & 1121 & 450 & $\sim 6$ & $40 \mathrm{~min}$ & Xie & 2003 \\
\hline $\mathrm{Pt}-\mathrm{Al}^{\mathrm{C}}$ & CMSX-4 & 1121 & 640 & $\sim 6$ & $40 \mathrm{~min}$ & Xie & 2003 \\
\hline Pt-Al & CMSX-4 & 1100 & 365 & 5.9 & $45 \mathrm{~min}$ & Baufeld & 2006 \\
\hline $\mathrm{Pt}-\mathrm{Al} \mathrm{vac}^{\mathrm{c}}$ & CMSX-4 & 1100 & 668 & 8.4 & $45 \mathrm{~min}$ & Baufeld & 2006 \\
\hline $\mathrm{Pt}-\mathrm{Al} \mathrm{H} 2 / \mathrm{Ar}^{\mathrm{c}}$ & CMSX-4 & 1100 & 1041 & 6.9 & $45 \mathrm{~min}$ & Baufeld & 2006 \\
\hline Pt-Al (1) & CMSX-4 & 1100 & 406 & & $50 \mathrm{~min}$ & Schulz & 2008 \\
\hline Pt-Al (1) & CMSX-4 & 1150 & 278 & & $50 \mathrm{~min}$ & Schulz & 2008 \\
\hline Pt-Al (1) $\mathrm{H}_{2} / \mathrm{Ar}$ & CMSX-4 & 1100 & 1157 & & $50 \mathrm{~min}$ & Schulz & 2008 \\
\hline $\mathrm{Pt}-\mathrm{Al}(2)$ & CMSX-4 & 1100 & 800 & & $50 \mathrm{~min}$ & Schulz & 2008 \\
\hline $\mathrm{Pt}-\mathrm{Al}(2)$ & CMSX-4 & 1150 & 420 & & $50 \mathrm{~min}$ & Schulz & 2008 \\
\hline $\mathrm{Pt}-\mathrm{Al}$ & CMSX-4 & 1100 & 545 & 5.9 & $1-\mathrm{h}$ & Sohn & 2015 \\
\hline Pt-Al & Gen 2 & 1150 & 550 & 6.1 & $1-h$ & Tolpygo & 2001 \\
\hline $\mathrm{Pt}-\mathrm{Al}^{\mathrm{c}}$ & Gen 2 & 1150 & 730 & 6.1 & $1-\mathrm{h}$ & Tolpygo & 2001 \\
\hline $\mathrm{Pt}-\mathrm{Al}$ & Gen 2 & 1150 & 190 & & $1-\mathrm{h}$ & Tolpygo & 2005 \\
\hline Pt-Al & Gen 2 & 1150 & 750 & & $1-\mathrm{h}$ & Tolpygo & 2005 \\
\hline Pt-Al pre-ox & Gen 2 & 1150 & 790 & & $1-\mathrm{h}$ & Tolpygo & 2005 \\
\hline Pt-Al pre-ox & Gen 2 & 1150 & 2870 & $>5$ & $1-\mathrm{h}$ & Tolpygo & 2005 \\
\hline Pt-Al & CMSX-10 & 1093 & 650 & & $100 \mathrm{~h}$ & Kimmel & 2000 \\
\hline $\mathrm{Pt}-\mathrm{Al}$ & CMSX-10 & 1038 & $>3400$ & & $100 \mathrm{~h}$ & Kimmel & 2000 \\
\hline Pt-Al high & PWA 1484 & 1135 & 435 & & $1-\mathrm{h}$ & $\mathrm{Wu}$ & 2008 \\
\hline Pt-Al low & PWA 1484 & 1135 & 322 & & $1-\mathrm{h}$ & $\mathrm{Wu}$ & 2008 \\
\hline Pt-Al & Rene'142 & 1100 & 817 & & $45 \mathrm{~min}$ & Lau & 2013 \\
\hline Pt-Al (1) & Rene'142 & 1100 & 823 & & $50 \mathrm{~min}$ & Schulz & 2013 \\
\hline Pt-Al (1) & IN100 & 1100 & 181 & & $50 \mathrm{~min}$ & Schulz & 2008 \\
\hline Pt-Al (1) $\mathrm{H}_{2} / \mathrm{Ar}$ & IN100 & 1100 & 600 & & $50 \mathrm{~min}$ & Schulz & 2008 \\
\hline $\mathrm{Pt}-\mathrm{Al}(2)$ & IN100 & 1100 & 509 & & $50 \mathrm{~min}$ & Schulz & 2008 \\
\hline $\mathrm{Pt}-\mathrm{Al}(2)$ & IN100 & 1150 & 150 & & $50 \mathrm{~min}$ & Schulz & 2008 \\
\hline $\mathrm{Pt}-\mathrm{Al}$ & IN100 & 1100 & 615 & & $50 \mathrm{~min}$ & Lau & 2013 \\
\hline Pt-Al & AM1 & 1100 & 1055 & & $1-\mathrm{h}$ & St.-Ramond & 2004 \\
\hline $\mathrm{S}-\mathrm{Pt}_{2} \mathrm{Al}_{3}$ & AM1 & 1100 & 1086 & & $1-\mathrm{h}$ & St.-Ramond & 2004 \\
\hline S-PtAl ${ }_{2}$ & AM1 & 1100 & 624 & & $1-\mathrm{h}$ & St.-Ramond & 2004 \\
\hline S-PtAl & AM1 & 1100 & 589 & & 1-h & St.-Ramond & 2004 \\
\hline \multicolumn{8}{|c|}{ b) Pt-only bond coats } \\
\hline Pt opt. & Rene'N5 & 1100 & 3536 & & $45 \mathrm{~min}$ & Yanar & 2011 \\
\hline Pt pre-ox & Rene'N5 & 1100 & 435 & & $45 \mathrm{~min}$ & Yanar & 2011 \\
\hline $\mathrm{Pt}$ & Rene'N5 & 1150 & 1447 & 9.1 & 1-h & Pint & 2015 \\
\hline $\mathrm{Pt}$ & CMSX-4 & 1150 & 400 & & $24 \mathrm{~h}$ & Tawancy & 2008 \\
\hline $\mathrm{Pt}$ & CMSX-4 & 1135 & 390 & 5.9 & $1-\mathrm{h}$ & $\mathrm{Wu}$ & 2008 \\
\hline Pt & PWA 1484 & 1135 & 1000 & $>9$ & $1-\mathrm{h}$ & $\mathrm{Wu}$ & 2008 \\
\hline $\mathrm{Pt}$ & 2Co Gen3 & 1150 & 351 & & $1-\mathrm{h}$ & $\mathrm{Wu}$ & 2008 \\
\hline $\mathrm{Pt}$ & 2Co Gen3 & 1170 & 382 & & $1-\mathrm{h}$ & $\mathrm{Wu}$ & 2008 \\
\hline $\mathrm{Pt}$ & 2Co Gen3 & 1190 & 205 & & $1-\mathrm{h}$ & $\mathrm{Wu}$ & 2008 \\
\hline Pt & 2Co Gen3 & 1210 & 108 & & $1-\mathrm{h}$ & $\mathrm{Wu}$ & 2008 \\
\hline $\mathrm{Pt}$ & 2Co Gen3 & 1230 & 61 & & $1-\mathrm{h}$ & $\mathrm{Wu}$ & 2008 \\
\hline
\end{tabular}


Table 1 (continued)

\begin{tabular}{|c|c|c|c|c|c|c|c|}
\hline Bond coat & Substrate & $\mathrm{T},{ }^{\circ} \mathrm{C}$ & $\mathrm{t}, \mathrm{h}$ & $\mathrm{x}_{\mathrm{c}}, \mu \mathrm{m}$ & Hot time/cycle & Study & \\
\hline \multicolumn{8}{|l|}{ b) Pt-only bond coats } \\
\hline Pt & 2Co Gen3 & 1250 & 88 & & 1-h & $\mathrm{Wu}$ & 2008 \\
\hline Pt & 2Co Gen3 & 1270 & 30 & & $1-\mathrm{h}$ & $\mathrm{Wu}$ & 2008 \\
\hline \multicolumn{8}{|c|}{ c) NiCoCrAlY bond coats } \\
\hline V-NiCoCrAlY & Rene'N5 & 1100 & 483 & 5.8 & $10 \mathrm{~min}$ & Kim & 2002 \\
\hline NiCoCrAlY low & Rene'N5 & 1100 & 148 & 4.8 & $45 \mathrm{~min}$ & Nijdam & 2006 \\
\hline NiCoCrAlY med & Rene'N5 & 1100 & 435 & 4.5 & $45 \mathrm{~min}$ & Nijdam & 2006 \\
\hline NiCoCrAlY high & Rene'N5 & 1100 & 150 & 3.8 & $45 \mathrm{~min}$ & Nijdam & 2006 \\
\hline Ar-NiCoCrAlY opt. & Rene'N5 & 1100 & 717 & & $45 \mathrm{~min}$ & Yanar & 2011 \\
\hline Ar-polished & Rene'N5 & 1100 & 473 & & $45 \mathrm{~min}$ & Yanar & 2011 \\
\hline Ar-NiCoCrAlY SOA & Rene'N5 & 1000 & 502 & & $45 \mathrm{~min}$ & Yanar & 2011 \\
\hline Ar-NiCoCrAlY SOA & Rene'N5 & 1100 & 53 & & $45 \mathrm{~min}$ & Yanar & 2011 \\
\hline Ar-NiCoCrAlY SOA & Rene'N5 & 1200 & 5 & & $45 \mathrm{~min}$ & Yanar & 2011 \\
\hline NiCoCrAlY & NiCoCrAlY & 1100 & 1777 & & $50 \mathrm{~min}$ & Schulz & 2013 \\
\hline V-NiCoCrAlY & Rene'142 & 1100 & 1939 & & $50 \mathrm{~min}$ & Schulz & 2013 \\
\hline NiCoCrAlY & Rene'142 & 1100 & 1695 & & $50 \mathrm{~min}$ & Schulz & 2008 \\
\hline NiCoCrAlY & Rene'142 & 1100 & $>1667$ & 8.0 & $50 \mathrm{~min}$ & Schulz & 2001 \\
\hline NiCoCrAlY & MarM002 & 1100 & $>1667$ & 8.2 & $50 \mathrm{~min}$ & Schulz & 2001 \\
\hline NiCoCrAlY (2) & IN 100 & 1100 & 1185 & & $50 \mathrm{~min}$ & Schulz & 2008 \\
\hline NiCoCrAlY (2) & IN 100 & 1150 & 393 & & $50 \mathrm{~min}$ & Schulz & 2008 \\
\hline NiCoCrAlY (1) & IN 100 & 1100 & 696 & & $50 \mathrm{~min}$ & Schulz & 2008 \\
\hline NiCoCrAlY (1) & IN 100 & 1150 & 160 & & $50 \mathrm{~min}$ & Schulz & 2008 \\
\hline NiCoCrAlY & IN 100 & 1100 & 708 & 7.1 & $50 \mathrm{~min}$ & Schulz & 2001 \\
\hline $\mathrm{NiCoCrAlY}+\mathrm{Hf}$ & IN 100 & 1100 & 760 & & $50 \mathrm{~min}$ & Schulz & 2008 \\
\hline V-NiCoCrAlY & IN 100 & 1100 & 421 & & $50 \mathrm{~min}$ & Schulz & 2008 \\
\hline NiCoCrAlY & CMSX-4 & 1100 & 333 & 5.3 & $50 \mathrm{~min}$ & Schulz & 2001 \\
\hline NiCoCrAlY (2) & CMSX-4 & 1100 & 519 & & $50 \mathrm{~min}$ & Schulz & 2008 \\
\hline NiCoCrAlY (2) & CMSX-4 & 1150 & 259 & & $50 \mathrm{~min}$ & Schulz & 2008 \\
\hline NiCoCrAlY (1) & CMSX-4 & 1100 & 60 & & $50 \mathrm{~min}$ & Schulz & 2008 \\
\hline $\mathrm{NiCoCrAlY}+\mathrm{Hf}$ & CMSX-4 & 1100 & 3911 & & $50 \mathrm{~min}$ & Schulz & 2008 \\
\hline $\mathrm{NiCoCrAlY}+\mathrm{Hf}$ & CMSX-4 & 1150 & 1060 & & $50 \mathrm{~min}$ & Schulz & 2008 \\
\hline V-NiCoCrAlY & CMSX-4 & 1100 & 441 & & $50 \mathrm{~min}$ & Schulz & 2008 \\
\hline NiCoCrAlY & PWA 1483 & 1100 & 167 & 4.5 & $50 \mathrm{~min}$ & Schulz & 2001 \\
\hline V-NiCoCrAlY & IN 738 & 1121 & 275 & 6.5 & $40 \mathrm{~min}$ & Sohn & 2001 \\
\hline $\mathrm{Pt}-\mathrm{Ar}-\mathrm{NiCoCrAlY}$ & Rene'N5 & 1100 & 698 & & $45 \mathrm{~min}$ & Yanar & 2002 \\
\hline Pt-Ar-NiCoCrAlY & Rene'N5 & 1100 & 803 & & $45 \mathrm{~min}$ & Yanar & 2011 \\
\hline Pt-V-NiCoCrAlYTa & AM3 & 1100 & 490 & 8.7 & 1-h & Vande Put & 2009 \\
\hline
\end{tabular}

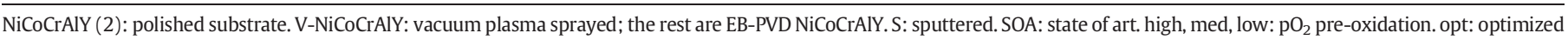
process. Ar: air plasma sprayed, Ar shroud.

a Extrapolated.

b $(\mathrm{Y}, \mathrm{Yb}, \mathrm{Gd}) \mathrm{SZ}$.

c No grit blast.

was to compare TBC coating lives to recent data being obtained for alumina-forming MAX phase substrates having low creep rates and minimal CTE mismatch with alumina or YSZ. These results have indicated coating survival with much larger scale thickness on the order of $30^{+} \mu \mathrm{m}$. This was achieved by successive $500 \mathrm{~h}$ exposures of APS and PS-PVD YSZ coatings on $\mathrm{Ti}_{2} \mathrm{AlC}$ at $1100,1150,1200,1250$, and $1300{ }^{\circ} \mathrm{C}$ (J. Smialek and B. Harder, ICACC 2015, Daytona Beach, unpublished research).

\section{Experimental factors}

The material/test conditions/failure times for the representative FCT results are listed in Table 1 . For the most part there are only a few distinguishing categories. Most were conducted in lab air, with 40-60 min of hot time per cycle. Depending on the study, cyclic bottom loading muffle furnaces or vertical and horizontal tube furnaces were used. No distinction has been made regarding cooling temperature, which is very important, although most attain $30-80{ }^{\circ} \mathrm{C}$ each cycle. It is well known that lower cooling temperatures, even near room temperature, and exposure to moisture, including ambient humidity, can accelerate scale spallation and TBC failure [14-21]. Typically a similar $2.54 \mathrm{~cm}$ dia. disc substrate sample was used for most Pt, Pt-Al bond coats, while $6 \mathrm{~mm}$ rods were used for many of the NiCoCrAlY bond coats (by Schulz and co-workers). Failure was defined as loss of at least $20-25 \%$ of the TBC coating area. Data entries may reflect average lives of multiple specimens, a range of lifetimes, or a single sample failure depending on what was available. Various process modifications that have demonstrated improvement are usually noted herein, while other less significant variants may not be addressed.

In a separate study, thermogravimetric (TGA) oxidation tests were performed on commercially produced Pt-modified CVD aluminide coatings on a 2nd generation single crystal superalloy (no top coat). The coupons tested in TGA were Howmet MDC150L standard Pt-aluminide coated CMSX-4, nominally having $0.1 \mathrm{wt}$.\% $\mathrm{Hf}$ and $<1 \mathrm{ppmw}$ S. However it is generally believed that some increased sulfur content is added in the coating by Pt-plating. Here, GDMS profiles of one TGA sample indicated $\sim 10$ ppmw $S$ at the outermost $1 \mu \mathrm{m}$ as-coated surface, decreasing to $\sim 0.05 \mathrm{ppmw}$, then increasing back to $1.5 \mathrm{ppmw}$ at a sputter depth of about $15 \mu \mathrm{m}$. Grit blasting with -200 mesh alumina at 20 psi increased the surface impurity level to $\sim 30 \mathrm{ppmw}$ S. Slowly flowing dry air was used for $100 \mathrm{~h}$ tests using a Setaram balance over the temperature range of $1000-1250{ }^{\circ} \mathrm{C}$.

\section{Results and discussion}

\subsection{Compiled FCT data}

\subsubsection{Overview of FCT studies cited}

The high temperature furnace cycle lives of EB-PVD YSZ coatings were normalized by hot time and presented in Table 1 ( $a, b$, and $c$ ). This table captures the longest lives reported in those studies, but may 
not include all the other variants that were not as durable (primary authors are often called out below to facilitate associating the coating results with a specific study). The first category includes no bond coats (NBC) and those exhibiting consistently among the highest lives at equivalent temperatures. Here bulk NiAl doped with small amounts of $\mathrm{Zr}$ or Hf for scale adhesion, as well as Ga and Ti for high temperature creep strength [22-24], was studied by Pint, Hazel, and coworkers. The latter system did not fail before testing was stopped. Along these lines, an overlay EB-PVD NiAl-5Cr-0.5Zr (at.\%) bond coat is listed, as it represented the highest $\mathrm{TBC}$ life compared to other $\mathrm{Cr}, \mathrm{Zr}$ contents for this overlay coating alloy [25] (Rigney et al.).

The next few groupings utilized various commercial or industrial platinum aluminide coatings (e.g., Howmet MDC150L) on single crystal superalloys, which are often viewed as state-of-the-art baselines for comparative purposes. This entails the common practice of electroplating nominally $\sim 5-10 \mu \mathrm{m}$ of Pt, then aluminizing in a lowactivity, high-temperature process to form nominally $\sim 40-75 \mu \mathrm{m}$ of $\beta$ $\mathrm{Ni}(\mathrm{Pt}) \mathrm{Al}$ as a bond coat. These are generally vacuum heat treated, then lightly grit blasted. Deposition of nominally 125-150 $\mu \mathrm{m}$ of the YSZ thermal barrier is achieved by EB-PVD.

Some studies also used modified (Y,Yb,Gd) SZ top coats [17,26] (Zhu, Smialek et al.). One study pre-oxidized the bond coat prior to YSZ top coating, and reported a broad distribution band of failure times [27] (Tolpygo and Clarke). Most of the superalloy substrates were 2nd generation single crystal superalloys, shown as Rene'N5, CMSX-4, PWA 1484, and generic compositions. These are among the most oxidation resistant superalloys because of their high $\mathrm{Al}$ and Ta content, and because there is $\leq 2 \mathrm{wt}$.\% detrimental Ti. They also contain a minor amount ( $0.1 \mathrm{wt} . \%)$ of $\mathrm{Hf}$ which is helpful for reducing alumina growth rates and for improving scale adhesion.

Four studies reflect lifetimes of diffused Pt-only bond coats [28-31] (Yanar, Pint, Tawancy, Wu, and coworkers), which have been proposed as effective lower cost and creep resistant alternative coatings for oxidation resistant single crystal superalloys. One of these studies systematically varied the Co content of a 3rd generation (high Re) composition and found that a low 2 wt.\% Co alloy provided the maximum TBC life compared to 8 or 12 wt.\% Co [30]. Other studies employed NiCoCrAlY bond coats [32-35] (Kim, Nijdam, Schulz, and coworkers) or a Pt coating over NiCoCrAlY(Ta) bond coat [36-38] (Yanar, Vande Put, and coworkers).

\subsubsection{Temperature effects of compiled FCT lives}

The TBC life distributions of Table 1 populate a trend-line with temperature as shown in Fig. 1. Taken as a group it reflects the strong detrimental effect of increasing temperature above $1100{ }^{\circ} \mathrm{C}$. More specific temperature effects (within a given study) are suggested by lines connecting lives of like samples. The bulk doped NiAl substrate data (triangles) show a clear separation from the vast majority of coating results. The latter are separated into various Pt-modified diffusion aluminide studies (diamonds, squares) and Pt-overlay bond coats (circles). Overall, these results define a mean behavior (dashed line) from linear regression, according to the following approximation:

logt $($ life, h $)=10.85-\left(7.22 \times 10^{-3}\right) \times \mathrm{T}(\AA \mathrm{C})$

with a correlation coefficient of just 0.57. A large amount of data is shown for the Pt-modified diffusion aluminide coatings on the Rene' N5 2nd generation single crystal superalloy (vertically split blue/red diamonds). The series from Pint et al. (ORNL) [22,23] occupies the upper band of all coating systems. This is believed to result from high purity laboratory Pt plating and CVD aluminizing compared to industrial scale processes. Accordingly, the lives reported in the five other investigations and laboratories are grouped more centrally and roughly 50\% lower.

Next we consider similar coatings on another 2nd generation single crystal superalloy, CMSX-4. Here the studies from the University of Connecticut (Profs. Jordan and Gell) can be discussed as a similar grouping (horizontally split blue/red diamond) [39-41] (Sridharan, Wen, Xie et al.). These help extend the trend-line to lower temperatures, but with one study [40] showing lives about $1 / 2$ the others. Two studies showed a life increase of $30-40 \%$ at $1150{ }^{\circ} \mathrm{C}$ and $1121{ }^{\circ} \mathrm{C}$ by not grit blasting [12,41]. The effect of pre-oxidation $\left(1150^{\circ} \mathrm{C}, 5 \mathrm{~h}\right.$, air; modified 2nd generation single crystal superalloy) provided another insight into improved performance by reducing the amount of transition alumina scales [27] (Tolpygo and Clarke, 2005). Here the maximum life of the pre-oxidized Pt-modified aluminide bond coat even approached the higher levels of the doped bulk NiAl substrates. However considerable scatter bands were reported for either untreated or pre-oxidized conditions. Other pre-treatment studies found improvements in $1100{ }^{\circ} \mathrm{C}$ tests, achieving up to 1000 h life [33,42] (Baufeld, Nijdam et al.).

\section{EB-PVD TBC FCT Life on Alumina-Forming Systems}

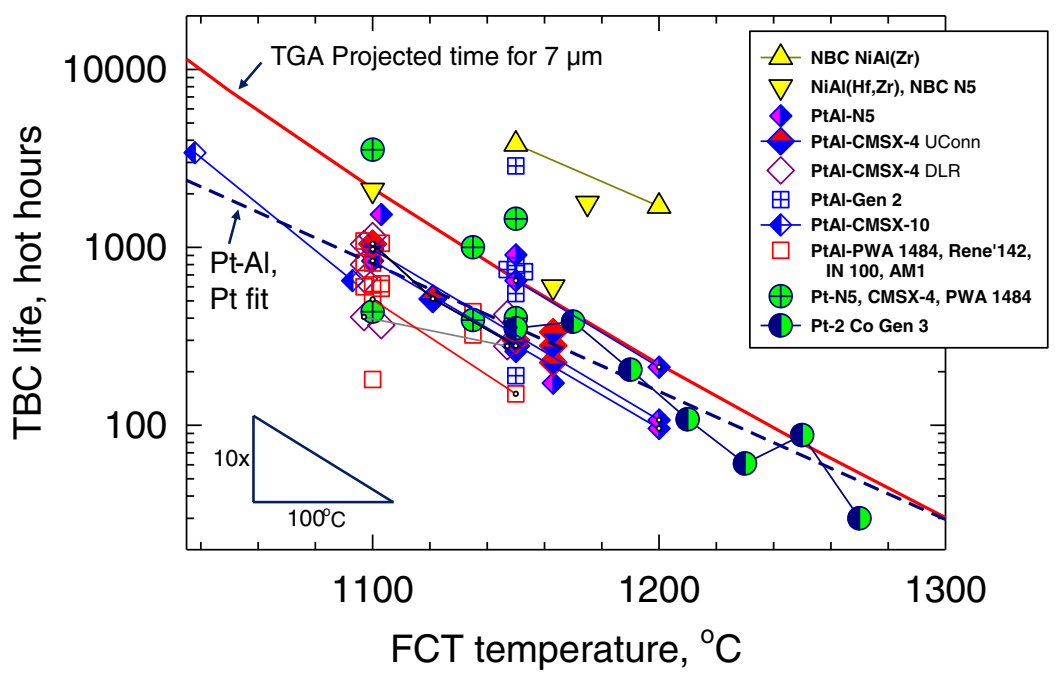

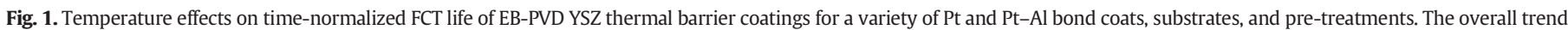
approaches a 10 -fold reduction for every $100{ }^{\circ} \mathrm{C}$ temperature increase. Overlapping points offset $\pm 3{ }^{\circ} \mathrm{C}$ for clarity. PtAl $=\mathrm{Pt}$-modified aluminide; Pt $=\mathrm{Pt}$-only diffused coatings. 
Additional results are presented for Pt-modified aluminide coatings on CMSX-10 (Gen 3), PWA 1484 (Gen 2), and AM1 (Gen 1). Lower temperature testing $\left(1038^{\circ} \mathrm{C}\right)$ resulted in lives $>3400 \mathrm{~h}[43]$. Some $33 \%$ life advantage was observed at $1135^{\circ} \mathrm{C}$ for a high activity aluminide compared to a low activity coating on PWA 1484 [31] (Wu et al.). Similar failure times (not shown) were reported for CMSX-4, TMS 138A, and TMS 82, substrates, which were all measurably higher than those for SRR99 substrates. Other substrates, tested at $1100{ }^{\circ} \mathrm{C}$ and $1150{ }^{\circ} \mathrm{C}$, include Rene'142, IN100, and AM1 (as reported by Lau, Schulz, SaintRamond, and co-workers) [38,44-46]. While these alloys are not single crystals, they exhibited lives comparable to the overall population.

The next category deals with Pt surface modification without aluminizing, Table 1 (b). These were pre-diffused into single crystal superalloys prior to EB-PVD top coating. A typical spread with some high values were obtained for Rene'N5, CMSX-4, and PWA 1484 (crossed green circles, Fig. 1). The characteristic trend was extended to higher temperatures for a $2 \mathrm{wt}$.\% Co 3rd generation single crystal superalloy (blue/green split circles) [30,31] (Wu), the latter spanning the largest temperature range in a single study. Failure times reported for other $8 \%$ and $12 \%$ Co versions (not shown) were roughly $2 / 3$ and $1 / 3$ the lives of the $2 \%$ Co alloy, respectively.

Data for NiCoCrAlY overlays, typically Ni-22Co-18Cr-14Al-0.2Y, are listed in Table 1 (c) and shown in Fig. 2, primarily in the $1100{ }^{\circ} \mathrm{C}-$ $1150{ }^{\circ} \mathrm{C}$ temperature regime. These show a strong influence of substrate alloy, thought to be related to the Hf or Y content of the superalloy [35] (Schulz et al.). The $1100{ }^{\circ} \mathrm{C}$ cyclic life ranged from about 200 to over 2000 cycles, the latter reaching the projected line for an upper bound discussed later. Pt modified NiCoCrAlY(Ta) bond coats on Rene'N5 (or AM3) produced FCT life at $1100{ }^{\circ} \mathrm{C}$ similar to Pt-modified aluminide bond coats, but at the lower end of the distribution [36,37] (Yanar, Rouaix-Vande Put et al.). On average, the NiCoCrAlY bond coats appeared to populate a life regime roughly $1 / 2$ that of the Pt-only $\gamma / \gamma^{\prime}$ or $\beta-\mathrm{Ni}(\mathrm{Pt}) \mathrm{Al}$ bond coats.

These summary plots of failure lives indicates a distribution that varies widely with alloy, bond coat, and investigation, but also within a given data set in some cases. The variation in life spans an order of magnitude at $1150{ }^{\circ} \mathrm{C}$, the most common test temperature. However, taking the population as a whole, the strong temperature dependence can still be surmised from the slope here as a life reduction of $~ 90 \%$ for every $100{ }^{\circ} \mathrm{C}$ increase in temperature, as originally identified independently by many studies $[10,32,39,40]$. Bulk doped NiAl(Hf,Zr) typically exhibited failure lives about $10 \times$ those reported for coatings. This level could not be approached by any other system except for the highest of the pre-oxidized Pt-modified aluminide coatings, representing samples that did not exhibit strong rumpling behavior [27] (data from Tolpygo and Clarke).

\subsection{Characteristic scale thickness}

It is not the intent of this note to review or critique failure mechanisms in detail, as proposed, for example, in [4,8-11] (namely the well-recognized works of Evans, Evans, Darolia, Strangman, DemasiMarcin et al.). Briefly, it is well known that thermal expansion differences with the substrate induce failure from the high compressive stresses on the scale and TBC. Indeed, strain energy, identified as the necessary criterion for TBC delamination, would be directly proportional to scale thickness and the square of CTE differentials as proposed by $\mathrm{H}$. E. Evans [8]. In addition, coating wear-out can occur by interdiffusion with the substrate, leading to non-protective scale formation, thick scales, and debonding of the YSZ topcoat. For EB-PVD TBC coatings, failure often occurs at the alumina scale - bond coat interface, presumably due to strong $\mathrm{YSZ}-\mathrm{Al}_{2} \mathrm{O}_{3}$ bonding. Higher exposure temperatures necessarily increase these $\Delta \alpha_{\text {CTE }} \Delta \mathrm{T}$ thermal stresses achieved on cool down as well as the rate and degree of interdiffusion. They also increase the growth rate of the scale on the bond coat. For the aluminide coatings, higher temperatures soften the bond coat, may exceed some phase stability boundaries and cause volume changes, thus producing mechanical instability (ratcheting, rumpling) during cooling. Repeated cycling exacerbates the problem and leads to a highly non-planar interface that cannot maintain contact with the rigid TBC. Lower cooling temperatures, coupled with ambient humidity contributes to higher stress and decreased interfacial toughness. Finally, any uncontrolled sulfur impurity is detrimental to scale adhesion, especially in the absence of Pt or reactive element dopants. Repeated scale spallation and crack growth in the TBC provide fatigue damage factors that lead to ultimate failure.

While evidence has often been presented to address all of these issues, they appear to operate synergistically, making isolation of individual contributions difficult without maintaining all other considerations fixed. One common figure of merit or simple failure criterion has been the 'critical thickness' of the scale formed on the bond coat (TGO) observed at failure. Thicker scales are intrinsically associated with greater strain energy, the driving force to overcome interfacial

\section{EB-PVD TBC FCT Life on NiCoCrAIY Bond Coats}

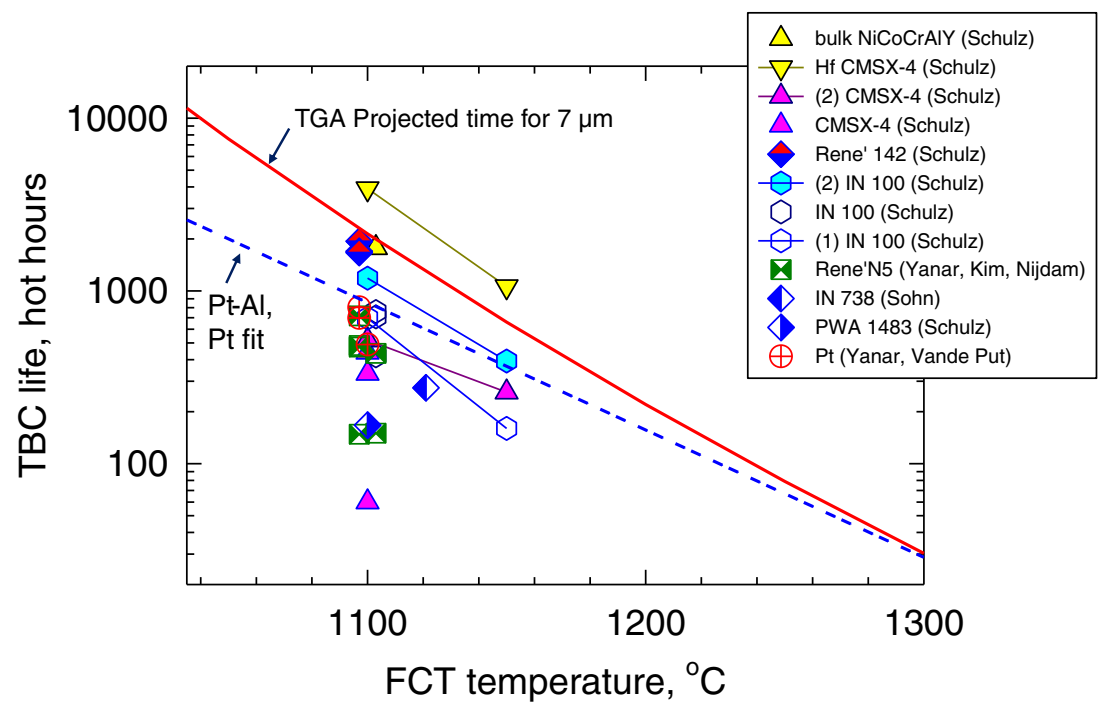

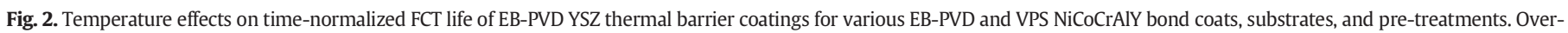
lapping points offset $\pm 3{ }^{\circ} \mathrm{C}$ for clarity. 
fracture toughness and allow instantaneous failure [8]. The growing scale also serves as a wedge between an increasingly rough TBC-TGO interface and gives rise to stress concentrations at the growing asperities and $\mathrm{Ni}(\mathrm{Pt}) \mathrm{Al}$ coating grain boundary ridges (roughness). These lead to premature local scale delamination from the bond coat and crack initiation in the TBC. Other factors may still be required for bond coat rumpling, occurring simultaneously and synergistically. On the other hand, Pt-only and NiCoCrAlY coatings do not generally exhibit surface rumpling because they are not subject to the same degree of creep, interdiffusion and phase instability issues upon thermal cycling.

Nevertheless, acknowledging that multiple factors drive failure, it is still somewhat instructive to examine scale growth kinetics as compared to the temperature dependence of TBC lives presented in Fig. 1. To that end, as-received Pt-modified aluminide 2nd generation single crystal superalloy coupons were isothermally oxidized at $1000^{\circ}-1250^{\circ} \mathrm{C}$ in air (TGA) for $100 \mathrm{~h}$ (unpublished research, J. Smialek). The regression fits of mass gain squared vs time were used to obtain the parabolic growth constants summarized in Table 2. A subsequent regression fit to the Arrhenius behavior of that data yielded the following (in $\mathrm{mg}^{2} / \mathrm{cm}^{4} \mathrm{~h}$ ):

$\mathrm{k}_{\mathrm{p}}=2.80 \times 10^{11} \exp (-382 \mathrm{~kJ} / \mathrm{mol} / \mathrm{RT})$.

This relation was then used to estimate the time necessary to produce a $7 \mu \mathrm{m}$ thick scale of $\alpha-\mathrm{Al}_{2} \mathrm{O}_{3}$ (assuming a fully dense scale and theoretical density of $\sim 5.34 \mathrm{~g} / \mathrm{cm}^{3}$ ). This thickness value arose from correlations with failure in a number of studies $[11,13,12,47]$, although we emphasize that it is not a strict, universal criterion, sufficient to trigger failure. Nevertheless, it is seen in Figs. 1 and 2 that only a handful of coating lives lie appreciably above the projected $7 \mu \mathrm{m}$ boundary. It has been discussed that the activation energy surmised from TBC life correlated with that obtained by oxidation and diffusion in alumina [34]. In that regard, the $382 \mathrm{~kJ} / \mathrm{mol}$ value obtained in Eq. (1) for the Pt-modified aluminide coating and that reported for Pt-Al bulk alloys, $356 \mathrm{~kJ} / \mathrm{mol}$ ( $85 \mathrm{kcal} / \mathrm{mol}$ ) [48] are essentially equivalent to the $375 \mathrm{~kJ} / \mathrm{mol}$ estimated for grain boundary diffusion of oxygen in alumina scales [49]. (This consistency only holds if there is little grain growth in the scales formed on these coatings.) Note that most coatings fail under this life boundary, suggesting that the additional complicating factors (geometry, edge cracking, Ti, substrate interdiffusion, poor sulfur control, grit blasting, rumpling, etc.) can affect various life reduction factors. Indeed, the $75 \%$ higher $1150{ }^{\circ} \mathrm{C} \mathrm{k}_{\mathrm{p}}$ measured for grit blasting (TGA results, Table 2) suggests a life boundary offset to just $\sim 0.6$ the projected $7 \mu \mathrm{m}$ as-coated life curve. Thus while grit blasting can be beneficial from the 1st order industrial standpoint of eliminating sporadic, premature 'infant mortality' by surface cleaning and leveling $\mathrm{NiAl}$ grain boundary ridges, there is also a 2nd order detriment due to adding low levels of impurities and/or increasing oxidation rates and surface roughness [50].

The critical thickness determined from the regression fit (Eq. (1)) is presented as the solid red line. (Alternately, 5 (or 10) $\mu \mathrm{m}$ scale

\section{Table 2}

Parabolic oxidation rate constants for Pt-modified aluminide coating on 2nd Gen single crystal superalloy.

\begin{tabular}{|c|c|c|c|c|}
\hline \multirow{2}{*}{$\begin{array}{l}\text { Temperature } \\
{ }^{\circ} \mathrm{C}\end{array}$} & \multicolumn{4}{|l|}{ (air, 100 h) } \\
\hline & $\begin{array}{l}\mathrm{k}_{\mathrm{p}} \\
\mathrm{mg} / \mathrm{cm}^{2} \mathrm{~h}\end{array}$ & $\begin{array}{l}\mathrm{k}_{\mathrm{p}} \\
\mu^{2} / \mathrm{h}\end{array}$ & $r^{2}$ & \\
\hline 1000 & $5.47 \mathrm{E}-05$ & $1.56 \mathrm{E}-03$ & 0.970 & \\
\hline 1050 & $1.59 \mathrm{E}-04$ & $4.53 \mathrm{E}-03$ & 0.991 & \\
\hline 1100 & $1.43 \mathrm{E}-03$ & $4.08 \mathrm{E}-02$ & 0.999 & \\
\hline 1150 & $2.75 \mathrm{E}-03$ & $7.84 \mathrm{E}-02$ & 0.999 & \\
\hline 1150 & $4.76 \mathrm{E}-03$ & $1.36 \mathrm{E}-01$ & 0.999 & Grit blast \\
\hline 1200 & $9.53 \mathrm{E}-03$ & $2.72 \mathrm{E}-01$ & 0.999 & \\
\hline 1250 & $1.57 \mathrm{E}-02$ & $4.48 \mathrm{E}-01$ & 0.999 & \\
\hline
\end{tabular}

\section{Alumina Scale Thickness at TBC Failure}

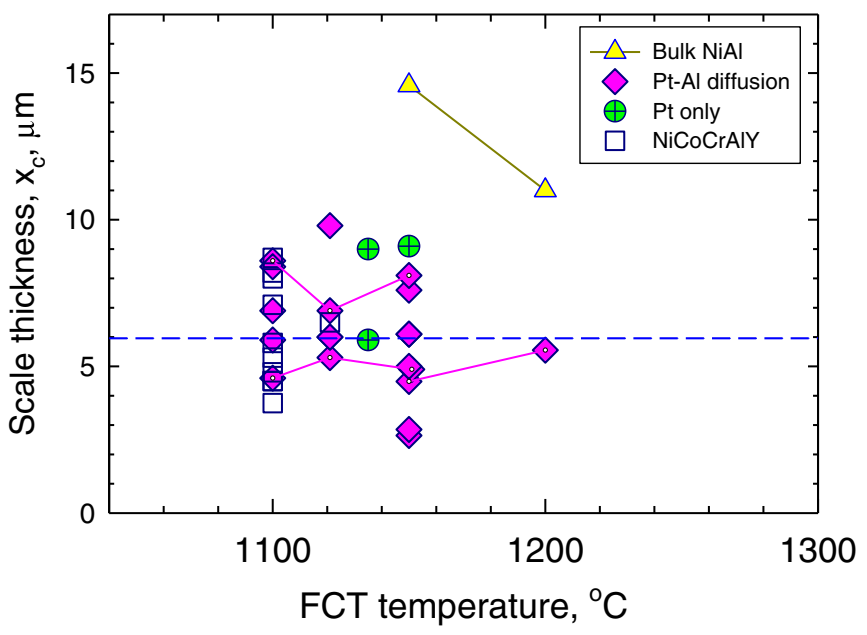

Fig. 3. Distribution of alumina scale thickness associated with TBC failure for various bond coats. No apparent overall trend with temperature (FCT of EB-PVD YSZ top coatings).

thicknesses could be chosen as failure criteria. These would produce corresponding times about $1 / 2$ ( or $2 \times$ ) that of the $7 \mu \mathrm{m}$ criterion, respectively.) It is seen that the time predicted to achieve the $7 \mu \mathrm{m}$ scale thickness is on the order of the higher life distributions for the Pt-only, Pt-modified aluminide, and NiCoCrAlY bond coatings.

The reported scale thickness at failure is also listed in Table 1, when available. They have been plotted in Fig. 3 to show the overall distribution and any trends that result. While some measurements were obtained directly from cross-sections, others were converted from weight change. The average (excluding the bulk NiAl substrates) was $6.1 \pm$ $1.8 \mu \mathrm{m}$. This range, while exhibiting considerable scatter, is close to the $7 \mu \mathrm{m}$ criterion. There appears to be no temperature dependence in this failure characteristic taken individually (connecting lines from one study) or as a group, as expected for a primary failure criterion. While higher temperatures insure somewhat higher $\Delta \alpha_{\text {CTE }}$ stresses, the shorter lifetimes (cycles) associated with higher temperatures would reduce cumulative fatigue damage. In any event, this apparent invariance of bond coat scale thickness at TBC failure is considered noteworthy. There does not appear to be a systematic difference in critical scale thickness between aluminized coatings vs Pt-only or MCrAlY overlays. The doped bulk $\mathrm{NiAl}(\mathrm{Zr})$ data, however, does indicate a different population because larger TGO scale thickness is attained for more extensive exposures before TBC failure, and with greater temperature effect. One conclusion would be that bulk $\mathrm{NiAl}(\mathrm{Zr})$ does not have the additional contributing factors of bond coat rumpling, allowing for thicker scales at TBC failure. These scales are then subject only to the strain energy criterion, which is temperature sensitive [8]. In fact, according to this criterion, the product of scale thickness and $(\Delta \mathrm{T})^{2}$ should be a constant, provided other material terms remain unchanged. Assuming a cooling temperature of $\sim 100^{\circ} \mathrm{C}$, it can be shown that the predicted scale thickness at failure in $1200{ }^{\circ} \mathrm{C}$ cyclic tests should be $\sim 0.8$ that predicted for $1100{ }^{\circ} \mathrm{C}$ tests. This variation would not be distinguished from scatter exhibited by the various bond coats, but is less than the trend shown for bulk $\mathrm{NiAl}(\mathrm{Zr})$ in Fig. 3.

Finally, It is recalled that grit blasting a PtAl-Gen2 TGA coupon produced a $\sim 75 \%$ increase in the oxidation rate at $1150{ }^{\circ} \mathrm{C}$, yielding a $\sim 40 \%$ reduction in the time to reach 'critical thickness' in Fig. 1. A 40\% reduction applied to the TGA fit lies closer to the central distribution of all the $1150^{\circ} \mathrm{C}$ failure lives for the Pt-modified aluminide coatings, which typically were grit blast. Without grit blasting, aluminide grain boundary ridge oxidation may still play a detrimental role in coating life. 


\subsection{Arrhenius behavior of FCT life}

On average, the slope of the TGA-projected scale thickness criterion (solid line in Fig. 1) suggests a life reduction of $~ 90 \%$ (representing a $10 \times$ factor) for every $100{ }^{\circ} \mathrm{C}$ increase in temperature. This is similar to the aggregate slope for the actual data, albeit the latter exhibiting large variability and a lower slope due to the multiple factors included in the population. The median behavior of the Pt-modified aluminide and Pt-only coatings shown by the dashed regression fitted line produced a slope closer to a $7.5 \times$ reduction for every $100^{\circ} \mathrm{C}$. That is because different studies, with offset lives representing different populations, dominate the low (Kimmel, Wen et al.) and high temperature (Wu) extremes [30,40,43].

The above correlation is quite consistent with failure mechanisms based in part on scale growth. In a more mechanistically based treatment, it can be shown that oxidative life $\left(t_{c}\right)$ should follow the form given by Eq. (3), if a fixed critical scale thickness, $x_{c}$, is assumed as follows:

$\mathrm{t}_{\mathrm{c}}=\mathrm{A}^{\prime} \exp (+\mathrm{Q} / \mathrm{RT})$

To that end, the aggregate Pt and Pt-modified aluminide data was combined and presented in the Arrhenius-type plot of Fig. 4. The overall trend yielded the regression fit (dashed line), with $\mathrm{A}^{\prime}=$ $2.09 \times 10^{-8}(\mathrm{~h})$ and again the low correlation factor, $\mathrm{r}^{2}=0.57$. The activation energy was $\sim 279 \mathrm{~kJ} / \mathrm{mol}$ compared to the $382 \mathrm{~kJ} / \mathrm{mol}$ found for coating oxidation alone (Eq. (2)). It is not believed that this difference represents anything significant, but rather just results from combining data of disparate studies.

The superior lives of the doped bulk NiAl substrates, with similar oxidation kinetics and scales, emphasizes the need for additional factors to fully explain the bond coat data. These factors typically include ratcheting/rumpling/interdiffusion effects that occur preferentially on the coated superalloys, but need not be discussed further for the purpose of this compilation. Other factors, also not discussed at length here, but deemed to be relevant for TBC life, would be the sulfur and reactive element contents of the system, ambient moisture content, and temperature achieved on cooling [18-20,51-54].

\section{Conclusions}

This presentation has catalogued published furnace cycle life (hot hours) of prevalent EB-PVD TBC systems vs temperature. The superalloy

\section{EB-PVD TBC FCT Life on Alumina-Forming Systems}

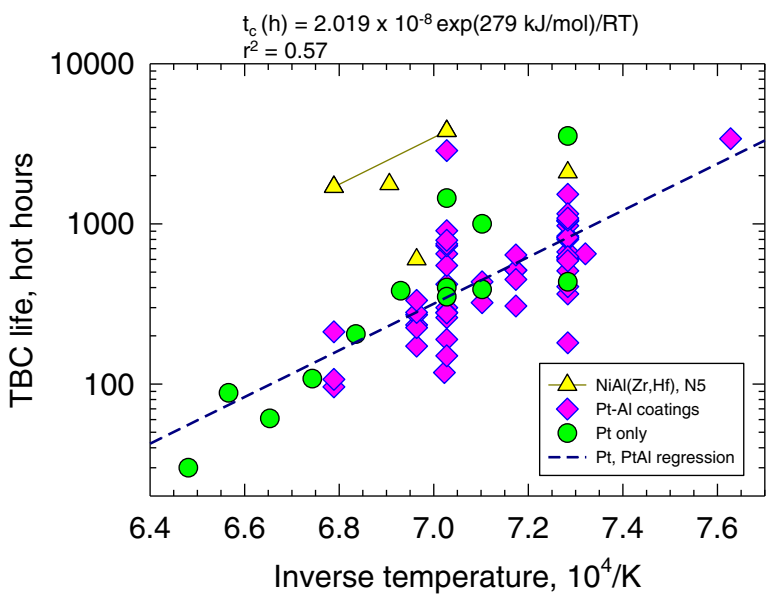

Fig. 4. Arrhenius behavior of FCT failure lives for EB-PVD YSZ thermal barrier coatings. No distinct differentiation by Pt-Al or Pt bond coats, except for bulk NiAl. Regression fit of all bond coat data indicates large scatter, but with an overall activation energy of $\sim 279 \mathrm{~kJ} / \mathrm{mol}$. substrates did not always exhibit a major effect on TBC life, partly because most examples given here were for similar oxidation resistant 2nd generation single crystal superalloys. Grit blasting exhibited higher oxidation rates and some negative effects within certain data sets. Yet most samples were grit blasted, with some still achieving lives near the upper limits of the population. Pt-diffused top coats provided a life benefit over the broader distribution, but did not necessarily overtake the upper limits achieved for some Pt-modified aluminide coatings. A significant life improvement was provided by an oxidation pretreatment (Tolpygo et al.), occasionally approaching values for bulk $\mathrm{NiAl}(\mathrm{Zr}, \mathrm{Hf})$ substrates (Pint and Rigney et al.). The bulk NiAl category was appreciably above the entire data set by avoiding detrimental bond coating/substrate interactions. Given those variations, the majority of the temperature dependent coating life population was quite graphically bounded by, and tracked with, oxidation kinetics. This upper bound for coatings was approximated (from TGA tests) by the time needed produce a scale thickness on the order of $7 \mu \mathrm{m}$, as previously identified in numerous TBC life tests. Lastly, the significance of this failure criterion is seen to be system specific in that much longer lives (and thicker scales) were produced on bulk $\mathrm{NiAl}(\mathrm{Zr})(15 \mu \mathrm{m})$ and are currently being found for $\mathrm{Ti}_{2} \mathrm{AlC}$ MAX phase substrates $\left(30^{+} \mu \mathrm{m}\right)$.

\section{Acknowledgments}

The author is grateful for helpful comments and shared information from Drs. U. Schulz, G. Meier, D. Zhu, and B. Pint. Ken Murphy (Alcoa/Howmet) is acknowledged for producing the Pt-modified aluminide coatings for TGA testing. This work was supported by the NASA Fundamental Aeronautics Program.

\section{References}

[1] S. R. Bell, D. S. Rickerby, and R. G. Wing, "US Patent 5,667,663 Method of Applying a Thermal Barrier Coating to a Superalloy Article and a Thermal Barrier Coating," 5,667,663, 1997.

[2] B. Gleeson, D. J. Sordelet, and W. J. Brindley, "US Patent 7,531,217 Methods for Making High-Temperature Coatings Having a Pt Modified Gamma Ni/Gamma Prime $\mathrm{Ni}_{3} \mathrm{Al}$ Alloy Compositions and a Reactive Element," 7,531,217, 2009.

[3] R. Miller, Current status of thermal barrier coatings - an overview, Surf. Coat. Technol. 30 (1987) 1-11.

[4] A.G. Evans, D.R. Mumm, J.W. Hutchinson, G.H. Meier, F.S. Pettit, Mechanisms controlling the durability of thermal barrier coatings, Prog. Mater. Sci. 46 (2001) 505-553.

[5] N.P. Padture, M. Gell, E.H. Jordan, Thermal barrier coatings for gas-turbine engine applications, Science 296 (2002) 280-284.

[6] J.R. Nicholls, Advances in coating design for high-performance gas turbines, MRS Bull. (Sept) (2003) 659-670.

[7] S. Bose, Thermal barrier coatings (TBCs), High Temperature Coatings, Elsevier, Amsterdam 2007, pp. 155-232.

[8] H.E. Evans, Oxidation failure of TBC systems: an assessment of mechanisms, Surf. Coat. Technol. 206 (7) (2011) 1512-1521.

[9] R. Darolia, Thermal barrier coatings technology: critical review, progress update, remaining challenges and prospects, Int. Mater. Rev. 58 (6) (2013) 315-348.

[10] T. Strangman, D. Raybould, A. Jameel, W. Baker, Damage mechanisms, life prediction, and development of EB-PVD thermal barrier coatings for turbine airfoils, Surf. Coat. Technol. 202 (4-7) (2007) 658-664.

[11] J.T. DeMasi-Marcin, K.D. Sheffler, S. Bose, Mechanisms of degradation and failure in a plasma-deposited thermal barrier coating, J. Eng. Gas Turbines Power 112 (1990) 521

[12] V.K. Tolpygo, D.R. Clarke, K.S. Murphy, Oxidation-induced failure of EB-PVD thermal barrier coatings, Surf. Coat. Technol. 146-147 (2001) 124-131.

[13] H. Dong, G.-J. Yang, C.-X. Li, X.-T. Luo, C.-J. Li, Effect of TGO thickness on thermal cyclic lifetime and failure mode of plasma-sprayed TBCs, J. Am. Ceram. Soc. 97 (33749) (2014) 1226-1232.

[14] J.L. Smialek, Effect of sulfur removal on $\mathrm{Al}_{2} \mathrm{O}_{3}$ scale adhesion, Metall. Trans. A 22 (3) (1991) 739-752.

[15] V.Sergo, D.R. Clarke, Observation of subcritical spall propagation of a thermal barrier coating. J. Am. Ceram. Soc. 81 (12) (1998) 3237-3242.

[16] J.L. Smialek, G.N. Morscher, Delayed alumina scale spallation on Rene'N5 + Y: moisture effects and acoustic emission, Mater. Sci. Eng. A 332 (1-2) (Jul. 2002) $11-24$.

[17] J.L. Smialek, D. Zhu, M.D. Cuy, Moisture-induced delamination video of an oxidized thermal barrier coating, Scr. Mater. 59 (1) (Jul. 2008) 67-70.

[18] M. Rudolphi, D. Renusch, M. Schütze, Verification of moisture-induced delayed failure of thermal barrier coatings, Scr. Mater. 59 (2) (2008) 255-257. 
[19] J.L. Smialek, Enigmatic moisture effects on $\mathrm{Al}_{2} \mathrm{O}_{3}$ scale and TBC adhesion, Mater. Sci. Forum 595-598 (2008) 191-198.

[20] V. Déneux, Y. Cadoret, S. Hervier, D. Monceau, Effect of water vapor on the spallation of thermal barrier coating systems during laboratory cyclic oxidation testing, Oxid. Met. 73 (1-2) (2010) 83-93.

[21] J.L. Smialek, Moisture-induced TBC spallation on turbine blade samples, Surf. Coat. Technol. 206 (7) (2011) 1577-1585.

[22] B.A. Pint, I.G. Wright, W.Y. Lee, Y. Zhang, K. Prüßner, K.B. Alexander, Substrate and bond coat compositions: factors affecting alumina scale adhesion, Mater. Sci. Eng. A 245 (1998) (1998) 201-211.

[23] B.A. Pint, I.G. Wright, W.J. Brindley, Evaluation of thermal barrier coating systems on novel substrates, J. Therm. Spray Technol. 9 (June) (2000) 198-203.

[24] B. Hazel, J. Rigney, M. Gorman, B. Boutwell, R. Darolia, Development of improved bond coat for enhanced turbine durability 1, Superalloys 2008 2008, pp. 753-760.

[25] D. Rigney, R. Darolia, W. Walston, R. Corderman, "'Nickel Aluminide Coating and Coating Systems Formed Therewith', US Patent 6,153,313.”, 2000.

[26] D. Zhu, R.A. Miller, M.A. Kuczmarski, Design and performance optimizations of advanced erosion-resistant low conductivity thermal barrier coatings for rotorcraft engines, NASA TM 2012-217138138, May 2012, pp. 1-5.

[27] V.K. Tolpygo, D.R. Clarke, The effect of oxidation pre-treatment on the cyclic life of EB-PVD thermal barrier coatings with platinum-aluminide bond coats, Surf. Coat. Technol. 200 (2005) 1276-1281.

[28] B.A. Pint, K.A. Unocic, J.A. Haynes, The effect of environment on TBC lifetime, ASME IGTI Exposition, Paper GT2015-43762 2015, pp. 1-10.

[29] H.M. Tawancy, A. Ul-Hamid, N.M. Abbas, M.O. Aboelfotoh, Effect of platinum on the oxide-to-metal adhesion in thermal barrier coating systems, J. Mater. Sci. 43 (2008) 2978-2989.

[30] R.T. Wu, R.C. Reed, On the compatibility of single crystal superalloys with a thermal barrier coating system, Acta Mater. 56 (2008) 313-323.

[31] R.T. Wu, K. Kawagishi, H. Harada, R.C. Reed, The retention of thermal barrier coating systems on single-crystal superalloys: effects of substrate composition, Acta Mater. 56 (2008) 3622-3629.

[32] G.M. Kim, N.M. Yanar, M.J. Stiger, M. Maris-Sida, F.S. Pettit, G.H. Meier, The effects of high temperature exposure on the durability of thermal barrier coatings, Key Eng. Mater. 197 (2001) 145-164.

[33] T.J. Nijdam, W.G. Sloof, Combined pre-annealing and pre-oxidation treatment for the processing of thermal barrier coatings on NiCoCrAlY bond coatings, Surf. Coat. Technol. 201 (2006) 3894-3900.

[34] K. Fritscher, U. Schulz, C. Leyens, Lifetime-determining spalling mechanisms of NiCoCrAIRE/EB-PVD zirconia TBC systems, Mater. Werkst. 38 (2007) 734-746.

[35] U. Schulz, M. Menzebach, C. Leyens, Y.Q. Yang, Influence of substrate material on oxidation behavior and cyclic lifetime of EB-PVD TBC systems, Surf. Coat. Technol. 146-147 (2001) 117-123.

[36] N.M. Yanar, G.H. Meier, F.S. Pettit, The influence of platinum on the failure of EBPVD YSZ TBCs on NiCoCrAlY bond coats, Scr. Mater. 46 (2002) 325-330.
[37] A. Vande Put, D. Oquab, A. Raffaitin, D. Monceau, Effect of Pt addition on the cyclic oxidation resistance of NiCoCrAlYTa base TBC systems, Proc. EUROCORR2009, Nice, Fr, September 6-10 2009, pp. 1-10.

[38] B. Saint-Ramond, M. Carlin, M. Silva, J.R. Nicholls, Low mass bondcoat for robust thermal barrier coatings, Mater. Sci. Forum 461-464 (2004) 265-272.

[39] S. Sridharan, L. Xie, E.H. Jordan, M. Gell, K.S. Murphy, Damage evolution in an electron beam physical vapor deposited thermal barrier coating as a function of cycle temperature and time, Mater. Sci. Eng. A 393 (2005) 51-62.

[40] M. Wen, E.H. Jordan, M. Gell, Effect of temperature on rumpling and thermally grown oxide stress in an EB-PVD thermal barrier coating, Surf. Coat. Technol. 201 (2006) 3289-3298.

[41] L. Xie, Y. Sohn, E.H. Jordan, M. Gell, The effect of bond coat grit blasting on the durability and thermally grown oxide stress in an electron beam physical vapor deposited thermal barrier coating, Surf. Coat. Technol. 176 (03) (2003) 57-66.

[42] B. Baufeld, U. Schulz, Life time dependency on the pre-coating treatment of a therma barrier coating under thermal cycling, Surf. Coat. Technol. 201 (2006) 2667-2675.

[43] J. Kimmel, Z. Mutasim, W. Brentnall, Effects of alloy composition on the performance of yttria stabilized zirconia-thermal barrier coatings, J. Eng. Gas Turbines Power 122 (July 2000) (2000) 393-400.

[44] H. Lau, Influence of yttria on the cyclic lifetime of YSZ TBC deposited on EB-PVD NiCoCrAIY bondcoats and its contribution to a modified TBC adhesion mechanism, Surf. Coat. Technol. 235 (2013) 121-126.

[45] U. Schulz, K. Fritscher, A. Ebach-Stahl, Cyclic behavior of EB-PVD thermal barrier coating systems with modified bond coats, Surf. Coat. Technol. 203 (5-7) (2008) 449-455.

[46] K. Fritscher, W. Braue, U. Schulz, Assessment of cyclic lifetime of NiCoCrAlY/ZrO based EB-PVD TBC systems via reactive element enrichment in the mixed zone of the TGO scale, Metall. Mater. Trans. A 44 (5) (2013) 2070-2082.

[47] V. Tolpygo, Grain coarsening in alumina scales and its effect on the oxidation kinetics of $\mathrm{Fe}-\mathrm{Cr}-\mathrm{Al}$ alloys, High Temperature Corrosion and Protection of Materials, 2008 (p. presentation).

[48] E.J. Felten, F.S. Pettit, Development, growth, and adhesion of $\mathrm{Al}_{2} \mathrm{O}_{3}$ on platinumaluminum alloys, Oxid. Met. 10 (3) (1976) 189-223.

[49] J.L. Smialek, Oxygen diffusivity in alumina scales grown on Al-MAX phases, Corros. Sci. 91 (Feb. 2015) 281-286

[50] J.A. Haynes, Potential influences of bond coat impurities and void growth on premature failure of EB-PVD TBCs, Scr. Mater. 44 (7) (2001) 1147-1152.

[51] J.L. Smialek, Improved oxidation life of segmented plasma sprayed 8YSZ thermal barrier coatings, J. Therm. Spray Technol. 13 (1) (Mar. 2004) 66-75.

[52] V.K. Tolpygo, K.S. Murphy, D.R. Clarke, Effect of Hf, Y and C in the underlying superalloy on the rumpling of diffusion aluminide coatings, Acta Mater. 56 (3) (2008) 489-499.

[53] J.L. Smialek, Moisture-induced delayed alumina scale spallation on a Ni(Pt)Al coating, Oxid. Met. 72 (5-6) (Jun. 2009) 259-278.

[54] D.L. Deadmore, C.E. Lowell, The effect of delta T (oxidizing temperature minus cooling temperature) on oxide spallation, Oxid. Met. 11 (2) (1977) 91-106. 